\title{
Maximization of the open circuit voltage for hydrogenated amorphous silicon $n-i-p$ solar cells by incorporation of protocrystalline silicon p-type layers
}

\author{
R. J. Koval, Chi Chen, G. M. Ferreira, A. S. Ferlauto, J. M. Pearce, P. I. Rovira, \\ C. R. Wronski, and R. W. Collins ${ }^{a)}$ \\ Center for Thin Film Devices, Department of Electrical Engineering, and Materials Research Institute, \\ The Pennsylvania State University, University Park, Pennsylvania 16802
}

(Received 11 April 2002; accepted for publication 17 June 2002)

\begin{abstract}
In studies of hydrogenated amorphous silicon $(a-\mathrm{Si}: \mathrm{H}) n-i-p$ solar cells fabricated by $\mathrm{rf}$ plasma-enhanced chemical vapor deposition (PECVD), we have found that the maximum open circuit voltage $\left(V_{\mathrm{oc}}\right)$ is obtained by incorporating $p$-type doped $\mathrm{Si}: \mathrm{H}$ layers that are protocrystalline in nature. Specifically, these optimum $p$ layers are prepared by PECVD in the $a$-Si:H growth regime using the maximum hydrogen-to-silane flow ratio possible without crossing the thickness-dependent transition into the mixed-phase (amorphous + microcrystalline) growth regime for the $\sim 200 \AA$ $p$-layer thickness. The strong dependence of the $p$-layer phase and solar cell $V_{\text {oc }}$ on the underlying $i$-layer phase also confirms the protocrystalline nature of the optimum Si:H $p$ layer. (C) 2002 American Institute of Physics. [DOI: 10.1063/1.1499735]
\end{abstract}

High open circuit voltages $\left(V_{\mathrm{oc}}\right)$ and record high efficiencies for hydrogenated amorphous silicon $(a-\mathrm{Si}: \mathrm{H})$ $n-i-p$ solar cells fabricated by rf plasma-enhanced chemical vapor deposition (PECVD) have been achieved by incorporating $p$-type doped $\mathrm{Si}: \mathrm{H}$ layers deposited at low temperature $\left(T \sim 200{ }^{\circ} \mathrm{C}\right)$ using high hydrogen-to-silane flow ratios (typically $\left.R \equiv\left[\mathrm{H}_{2}\right] /\left[\mathrm{SiH}_{4}\right] \sim 50-200\right) .{ }^{1-3}$ It was proposed that such optimum $p$ layers are, in fact, microcrystalline $\mathrm{Si}: \mathrm{H}$ $(\mu c-\mathrm{Si}: \mathrm{H})$ and that this material yields improved cell performance through an increase in the built-in potential of the junction and through decreases in series resistance and absorption losses.

In Ref. 1, the high conductivities characteristic of $\mu c$-Si:H were measured only on thick $p$ layers $(>1000 \AA)$; however, the layers incorporated into the devices were much thinner $(\sim 100 \AA)$. In subsequent studies, the $V_{\text {oc }}$ values obtained with $p$ layers prepared by PECVD at high $R$ were found to increase further as the $p$-layer deposition temperature $(T)$ was decreased. ${ }^{2,3}$ To explain this behavior, an increase in $p$-layer crystallinity with decreasing $T$ was hypothesized, yet just the opposite trend for $T<400{ }^{\circ} \mathrm{C}$ had been described earlier for four different sets of PECVD films. ${ }^{4}$ Reflection high energy electron diffraction (RHEED) patterns were also presented as evidence that the optimum $p$ layers were $\mu c-\mathrm{Si}: \mathrm{H}^{3}$ RHEED is a highly surface-sensitive technique, however, and so fails to probe the $p$-layer material closest to the $i / p$ junction.

In view of these considerations, an explanation of the high $V_{\text {oc }}$ values of Refs. $1-3$ in terms of a $\mu c-\mathrm{Si}: \mathrm{H} p$ layer is not compelling owing to a possible barrier for microcrystal nucleation on an amorphous $i$-layer surface. ${ }^{5-7}$ As a result, 100-200- $\AA$-thick $p$ layers prepared on $i$ layers under certain conditions may be amorphous even at $R$ values as high as $200 .^{8}$ In the present study, the problem of $\mathrm{Si}: \mathrm{H} p$-layer opti-

a)Electronic mail: rwc6@psu.edu mization has been reconsidered. Light and dark currentvoltage characteristics dominated by bulk recombination for state-of-the-art $a$-Si:H $n-i-p$ solar cells ${ }^{9}$ have been correlated with spectroscopic ellipsometry (SE) results for the corresponding $p$ layers of the $n-i-p$ structures.

Three experimental approaches were applied for $p$-layer optimization in $a$-Si:H solar cells.

(1) $\mathrm{Si}: \mathrm{H} p$ layers for use in $p-i-n$ solar cells were developed for high nucleation density and single-phase microcrystalline structure in 100 - $\AA$-thick films on glass $/ \mathrm{ZnO}$ and glass $/ \mathrm{SnO}_{2} / \mathrm{ZnO}$ substrates using a single-chamber rf PECVD system and guidance from real time SE (RTSE). In this approach, $p$-layer gas mixtures of $\left[\mathrm{H}_{2}\right] /\left[\mathrm{SiH}_{4}\right] /\left[\mathrm{B}\left(\mathrm{CH}_{3}\right)_{3}\right]$ were used, and a deposition phase diagram revealed the preferred conditions of $R$ $=200$ and $D=\left[\mathrm{B}\left(\mathrm{CH}_{3}\right)_{3}\right] /\left[\mathrm{SiH}_{4}\right]=0.02$ for immediate high-density $\mu c$-Si:H nucleation on $\mathrm{ZnO} .{ }^{10}$ The $p-i-n$ cell structures incorporated an $R=0 i$ layer to avoid possible $p$-layer substrate-induced microcrystallinity. ${ }^{7}$

(2) $\mathrm{Si}: \mathrm{H} p$ layers for use in $n-i-p$ cells were developed in a similar manner as the $p$ layers for $p-i-n$ cells. In this approach, however, the underlying $i$-layer surface was subjected to a 2 min $\mathrm{H}_{2}$-plasma treatment that generates nanocrystalline $\mathrm{Si}: \mathrm{H}$ nucleation sites for the $p$-layer deposition. A wide window for single-phase $\mu c-\mathrm{Si}: \mathrm{H}$ was found using $\left[\mathrm{H}_{2}\right] /\left[\mathrm{SiH}_{4}\right] /\left[\mathrm{BF}_{3}\right]$ mixtures with $D$ $=\left[\mathrm{BF}_{3}\right] /\left[\mathrm{SiH}_{4}\right]=0.2$ and $R=200 .^{8}$ This preferred $p$-layer process was then adopted for $n-i-p$ cells on Cr-coated glass using an $R=10 i$ layer.

(3) After fabrication of $p-i-n$ and $n-i-p$ solar cells with $p$ layers designed for dense, single-phase $\mu c-\mathrm{Si}: \mathrm{H}$ structure, a number of state-of-the-art $n-i-p$ devices were fabricated on $\mathrm{Cr}$-coated glass in a multichamber $\mathrm{rf}$ PECVD system under a variety of $p$-layer conditions. For all such cells, the $i$ layer was deposited to $4000 \AA$ with $R=10$, but the $\mathrm{H}_{2}$-plasma treatment was eliminated 
to avoid any direct substrate-induced microcrystallinity in the overlying $p$ layers. ${ }^{7,8}$ In this third approach, $\mathrm{BF}_{3}$ doping gas was used with $D=0.2$, and $R$ was varied from 50 to 200. Solar cells with and without a $200-\AA$ thick $R=40 a$-Si:H $i$-layer region ${ }^{6}$ deposited just prior to the $p$ layer were also compared to assess $i$ layer substrate-dependent effects on the $p$ layer.

For all three high $R p$-layer deposition approaches listed above, the substrate temperature was fixed at $200{ }^{\circ} \mathrm{C}$ and the rf plasma power was in the range of $0.3-0.8 \mathrm{~W} / \mathrm{cm}^{2}$. Where appropriate, the $V_{\mathrm{oc}}$ values obtained from solar cells incorporating the high $R p$ layers were compared to the values obtained from cells incorporating a standard $R=0$ $a-\mathrm{Si}_{1-x} \mathrm{C}_{x}: \mathrm{H} p$ layer with composition $x \sim 0.1$. In the latter $p$-layer process, a gas mixture of $\left[\mathrm{SiH}_{4}\right] /\left[\mathrm{CH}_{4}\right] /\left[\mathrm{B}\left(\mathrm{CH}_{3}\right)_{3}\right]$ was used with $D=0.01, z=\left[\mathrm{CH}_{4}\right] /\left\{\left[\mathrm{SiH}_{4}\right]+\left[\mathrm{CH}_{4}\right]\right\}=0.5$, and an rf plasma power of $0.05 \mathrm{~W} / \mathrm{cm}^{2}$.

In approaches (1) and (2), RTSE (1.5-4 eV) was performed using a multichannel instrument. ${ }^{11}$ In approach (3), ex-situ SE (1.5-5.5 eV) was performed on identical glass/ $\mathrm{Cr} / n-i-p$ structures cofabricated with the solar cells. Phase determinations by SE were corroborated by atomic force microscopy (AFM) and electron microscopies.

First, the final outcome will be summarized for the characterization of $a-\mathrm{Si}: \mathrm{H} p-i-n$ and $n-i-p$ solar cells incorporating the preferred single-phase $\mu c-\mathrm{Si}: \mathrm{H} p$ layers developed with guidance from RTSE according to approaches (1) and (2) above. For $a$-Si:H $p-i-n$ solar cells deposited on $\mathrm{ZnO}$ with an $R=0 i$ layer, the $\mu c$-Si:H $p$-layer process gave $V_{\mathrm{oc}}=0.64 \mathrm{~V}$. This value is much lower than the baseline of $0.81 \mathrm{~V}$, which is obtained for $p-i-n$ cells fabricated under identical conditions, but using the standard $a-\mathrm{Si}_{1-x} \mathrm{C}_{x}: \mathrm{H}$ process designed to ensure a purely amorphous $p$ layer. For $a$-Si:H $n-i-p$ cells with an $R=10 i$ layer, the $\mu c-\mathrm{Si}: \mathrm{H} p$ layer process gave $V_{\mathrm{oc}}=0.76 \mathrm{~V}$, again much lower than the corresponding baseline of $0.88 \mathrm{~V}$. Such results demonstrate that deposition processes designed to maximize microcrystalline nucleation density and volume fraction for $100 \AA p$ layers do not optimize $V_{\text {oc }}$ for $a-\mathrm{Si}: \mathrm{H} p-i-n$ and $n-i-p$ solar cells, and that record high efficiencies are unlikely for cells incorporating purely $\mu c-\mathrm{Si}: \mathrm{H} p$ layers.

Thus, it is important to re-address this problem by considering state-of-the art solar cells fabricated by multichamber PECVD and incorporating $p$ layers deposited using a variation in $R$ according to approach (3) above. In this way, the phase of the $p$ layer can be varied from pure amorphous $\mathrm{Si}: \mathrm{H}$ through mixed-phase amorphous + microcrystalline $\mathrm{Si}: \mathrm{H}[(a+\mu c)-\mathrm{Si}: \mathrm{H}]$. Figure 1 shows $V_{\text {oc }}$ for the series of $n-i-p$ solar cells incorporating $p$ layers prepared with $D$ $=\left[\mathrm{BF}_{3}\right] /\left[\mathrm{SiH}_{4}\right]=0.20$, but with different $R$ values over the range $50 \leqslant R \leqslant 200$.

Also plotted versus $R$ in Fig. 1 is the microcrystalline silicon volume fraction in the $p$ layer as obtained by $e x$-situ $\mathrm{SE}$ in the actual $n-i-p$ solar cell configuration. Leastsquares regression analyses applying the Bruggeman effective medium theory were performed for the determination of the microcrystalline fractions of the $p$ layers, assuming a three-component mixture of $a-\mathrm{Si}: \mathrm{H} / \mu c-\mathrm{Si}: \mathrm{H} /$ void. $^{5}$ The component dielectric function for single-phase $\mu c-\mathrm{Si}: \mathrm{H}$ in Downloaded 19 Aug 2002 to 130.203 .199 .192 . Redistribution subjec

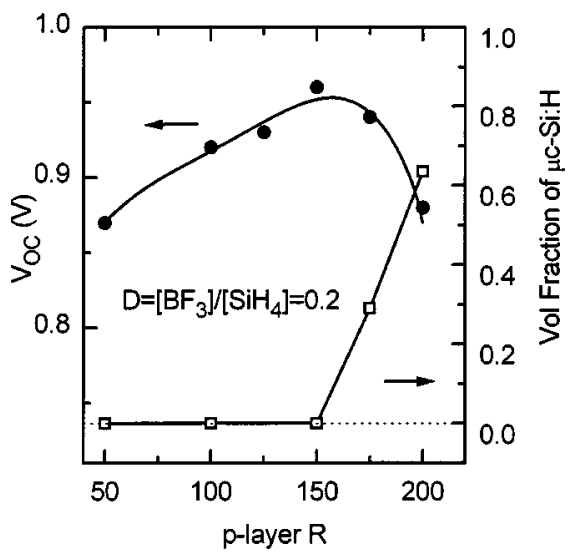

FIG. 1. Open circuit voltage $V_{\text {oc }}$ (left scale) plotted vs the $p$-layer $R$ $=\left[\mathrm{H}_{2}\right] /\left[\mathrm{SiH}_{4}\right]$ value for a series of $a-\mathrm{Si}: \mathrm{H} n-i-p$ solar cells with one-step $R=10 i$ layers (solid points). The $p$-layer microcrystalline $\mathrm{Si}: \mathrm{H}$ volume fractions (right scale) are also included, as measured by SE in the actual $n-i-p$ cell configuration (open points).

these analyses was obtained in studies of a 200- $\AA$-thick $p$ layer prepared on $\mathrm{H}_{2}$ plasma treated $a$-Si:H at $200{ }^{\circ} \mathrm{C}$ using a $\left[\mathrm{H}_{2}\right] /\left[\mathrm{SiH}_{4}\right] /\left[\mathrm{BF}_{3}\right]=200 / 1 / 0.1$ gas mixture. This $p$ layer was measured by RTSE during growth ${ }^{8}$ and then upon cooling to $25^{\circ} \mathrm{C}$. The component dielectric function for singlephase $a$-Si:H was obtained from an $R=10 a$-Si:H film using ex-situ SE. In Fig. 2, the true optical properties (corrected for surface roughness overlayers) are presented for (a) the $R$ $=150 \mathrm{p}$ layer with no detectable microcrystalline phase $(<0.02$ in vol. fraction) and (b) the $R=200 p$ layer with the highest microcrystalline content ( 0.63 in vol. fraction), incorporated within the cells with the highest $V_{\mathrm{oc}}(0.96 \mathrm{~V})$ and reduced $V_{\mathrm{oc}}(0.88 \mathrm{~V})$ values, respectively. The fact that the $p$ layer in Fig. 2(b) is mixed-phase $(a+\mu c)-\mathrm{Si}: \mathrm{H}$, rather than single-phase $\mu c-\mathrm{Si}: \mathrm{H}$, may be accounted for by the absence of an $i$-layer $\mathrm{H}_{2}$-plasma pretreatment. ${ }^{8}$

The electrical properties of the $p$ layers reveal overall similar trends. For thin $(<1000 \AA) R=100 p$ layers deposited on $i$ layers, a thickness-dependent conductivity $(\sigma)$ and conductivity activation energy $\left(E_{\sigma}\right)$ are observed with relatively high values of $E_{\sigma} \sim 0.5 \mathrm{eV}$, attributed to transport dominated by the amorphous phase (but with an increasing influence of the microcrystalline phase with thickness). In contrast, thin $p$ layers with $R=200$ exhibit thicknessindependent properties with $E_{\sigma} \sim 0.1 \mathrm{eV}$, attributed to transport dominated by the microcrystalline phase.

Thus, from the overall results presented here, it is clear that the maximum $V_{\mathrm{oc}}$ is obtained for the cell incorporating the $p$ layer deposited at the maximum possible $R$, while remaining just below the amorphous-to-(mixed-phase amorphous + microcrystalline) $\quad[a \rightarrow(a+\mu c)]$ transition throughout the $200 \AA$ thickness of the $p$ layer. In fact, this is the same optimization criterion as is applied for one-step $i$ layers to maximize not only $V_{\text {oc }}$ but also the fill factor stability against light-induced degradation. ${ }^{6}$ Thus, we conclude that $V_{\mathrm{oc}}$ is maximized when the $p$ layer is prepared in the protocrystalline $\mathrm{Si}: \mathrm{H}$ state and that the overall highest solar cell performance in annealed and degraded states is attained by using protocrystalline $\mathrm{Si}: \mathrm{H}$ for both $p$ and $i$ layers.

There are two key characteristics that identify the growth regime yielding protocrystalline $\mathrm{Si}: \mathrm{H}^{6}{ }^{6}$ The first characteristo AIP license or copyright, see http://ojps.aip.org/aplo/aplcr.jsp 

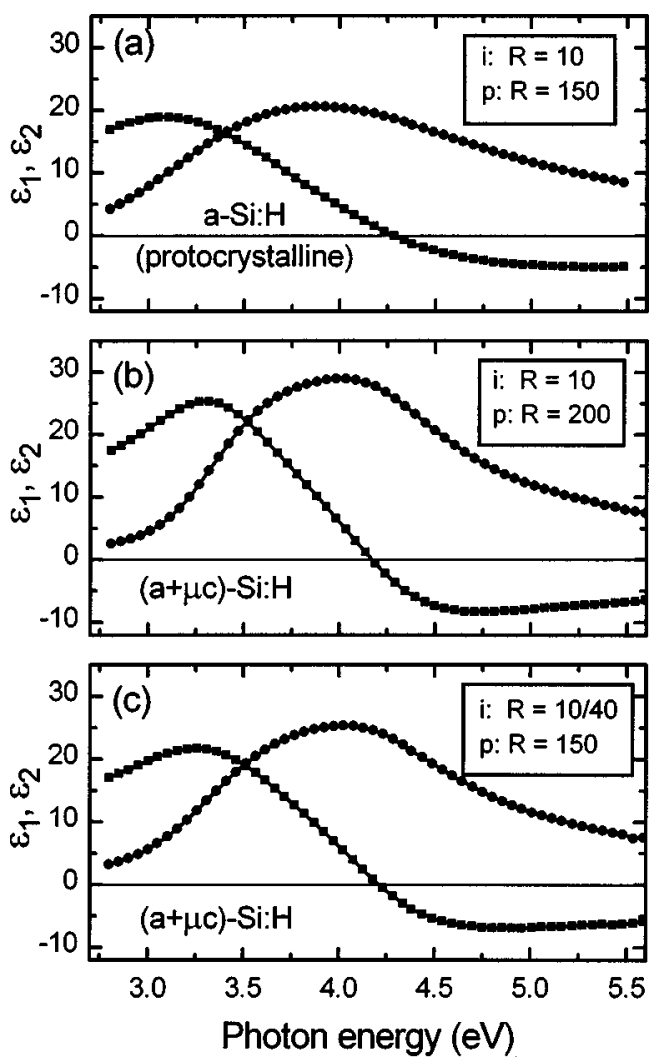

FIG. 2. Real and imaginary parts of the dielectric functions $\left(\varepsilon_{1}, \varepsilon_{2}\right)$ of the $p$ layers of $a$-Si:H $n-i-p$ solar cells incorporating (a) a one-step $R=10$ $a$-Si:H $i$ layer and $R=150$ protocrystalline $\mathrm{Si}: \mathrm{H} p$ layer; (b) a one-step $R$ $=10 a-\mathrm{Si}: \mathrm{H} i$ layer and $R=200(a+\mu c)-\mathrm{Si}: \mathrm{H} p$ layer; and (c) a two-step $R=10 / R=40 \quad i$ layer and $R=150 p$ layer with substrate-induced $(a$ $+\mu c)-\mathrm{Si}: \mathrm{H}$ structure.

tic is the accumulated thickness dependence of the phase of the growing material. Although the term "protocrystalline" describes an amorphous Si:H phase, given sufficient thickness protocrystalline $\mathrm{Si}: \mathrm{H}$ ultimately evolves-as its name implies-first to mixed-phase $(a+\mu c)-\mathrm{Si}: \mathrm{H}$ and finally to single-phase $\mu c-\mathrm{Si}: \mathrm{H}$. A second characteristic of protocrystalline $\mathrm{Si}: \mathrm{H}$ is the substrate dependence of the phase evolution. Under protocrystalline growth conditions, microcrystalline nucleation is suppressed on an underlying $a$-Si:H film; however, under the same deposition conditions local epitaxy is favored on underlying $\mu c-\mathrm{Si}: \mathrm{H}$.

To demonstrate the latter effect, Fig. 2(c) provides the dielectric function for the $p$ layer of a $n-i-p$ solar cell fabricated under conditions identical to those of the optimum cell of Fig. 2(a), with the only difference being the incorporation of a $200 \AA R=40$ interface $i$ layer ${ }^{6}$ between the $R$ $=10$ bulk $i$ layer and the overlying $R=150 p$ layer. Also shown in Fig. 3 is a comparison between the resulting solar cell $I-V$ characteristics in the annealed state for (i) the optimum cell of Fig. 2(a) with the one-step $R=10 i$ layer and the $R=150 p$ layer, and (ii) the cell of Fig. 2(c) with the two-step $R=10 / R=40 i$ layer and the identically-prepared $R=150 p$ layer. Two important effects are observed in Figs. 2 (c) and 3. First, microcrystalline nuclei at the top surface of the $R=40$ interface $i$ layer, as detected by AFM in $p-i-n$ studies, induce microcrystallites in the $p$ layer. In fact, the volume fraction of microcrystalline phase in the $p$ layer in-

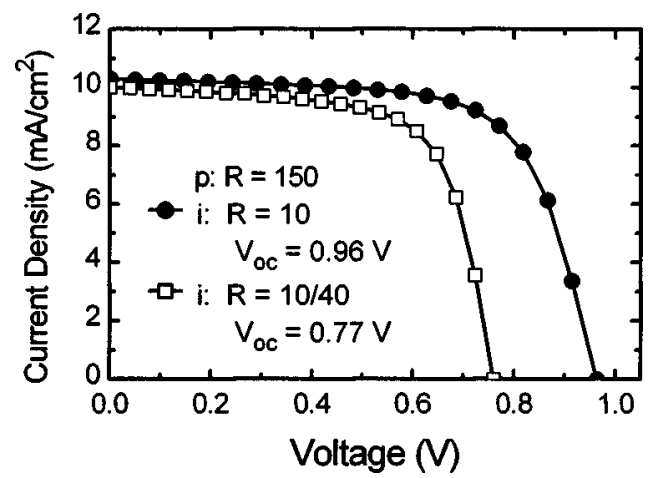

FIG. 3. Annealed state $I-V$ characteristics for the optimum $a-\mathrm{Si}: \mathrm{H} n-i-p$ solar cell of Fig. 2(a) with the $R=150$ protocrystalline $\mathrm{Si}: \mathrm{H} p$ layer (solid symbols), and for the $n-i-p$ cell of Fig. 2(c) fabricated under otherwise identical conditions, but incorporating a $200 \AA R=40 \mathrm{Si}: \mathrm{H} i$ layer at the $i / p$ junction (open symbols).

creases from undetectable levels $(<0.02)$ to 0.31 with the addition of the $R=40$ interface $i$ layer. Second, $V_{\mathrm{oc}}$ of the resulting solar cell drops from 0.96 to $0.77 \mathrm{~V}$ due to this increase in $p$ layer microcrystalline fraction. These results further demonstrate that protocrystalline $\mathrm{Si}: \mathrm{H} p$ layers optimize $V_{\mathrm{oc}}$, and that even relatively low substrate-induced microcrystalline fractions in the $p$ layer are detrimental.

In conclusion, we have re-addressed the issue of $p$-layer optimization for $a$-Si:H solar cells, finding that the maximum open circuit voltage $\left(V_{\mathrm{oc}}\right)$ in $n-i-p$ solar cells is obtained using $p$ layers that are protocrystalline in nature, i.e., deposited at the maximum possible $R=\left[\mathrm{H}_{2}\right] /\left[\mathrm{SiH}_{4}\right]$ without traversing the transition from the $a-\mathrm{Si}: \mathrm{H}$ growth regime to the mixed-phase $(a+\mu c)$-Si:H regime for the $\sim 200 \AA p$-layer thickness. The higher $V_{\text {oc }}$ values may be due to the wider mobility gaps for the protocrystalline $\mathrm{Si}: \mathrm{H} p$ layers that are also observed in the case of the $i$ layers. ${ }^{7}$ Owing to the protocrystalline nature of $p$-layer growth, any microcrystalline silicon nuclei in the underlying $i$ layer, for example, due to excessive $\mathrm{H}_{2}$-dilution, induce microcrystallinity in the $p$ layer, which reduces $V_{\mathrm{oc}}$.

The authors acknowledge support of this research by NREL (subcontract Nos. XAF-8-17619-22 and AAD-9-18668-09) and by NSF (Grant No. DMR-0137240).

${ }^{1}$ S. Guha, J. Yang, P. Nath, and M. Hack, Appl. Phys. Lett. 49, 218 (1986).

${ }^{2}$ A. Banerjee, Sol. Energy Mater. Sol. Cells 36, 295 (1995).

${ }^{3}$ X. Deng, S. J. Jones, T. Liu, M. Izu, S. R. Ovshinsky, and K. Hoffman, Mater. Res. Soc. Symp. Proc. 467, 795 (1997).

${ }^{4}$ S. Vepřek, F.-A. Sarott, and M. Rückschloß, J. Non-Cryst. Solids 137\&138, 733 (1991)

${ }^{5}$ R. W. Collins, A. H. Clark, S. Guha, and C.-Y. Huang, J. Appl. Phys. 57, 4566 (1985)

${ }^{6}$ J. Koh, Y. Lee, H. Fujiwara, C. R. Wronski, and R. W. Collins, Appl. Phys. Lett. 73, 1526 (1998).

${ }^{7}$ J. Koh, A. S. Ferlauto, P. I. Rovira, C. R. Wronski, and R. W. Collins, Appl. Phys. Lett. 75, 2286 (1999).

${ }^{8}$ J. Koh, H. Fujiwara, R. J. Koval, C. R. Wronski, and R. W. Collins, J. Appl. Phys. 85, 4141 (1999).

${ }^{9}$ J. M. Pearce, R. J. Koval, A. S. Ferlauto, R. W. Collins, C. R. Wronski, J. Yang, and S. Guha, Appl. Phys. Lett. 77, 3093 (2000).

${ }^{10}$ P. I. Rovira, A. S. Ferlauto, R. J. Koval, C. R. Wronski, R. W. Collins, and G. Ganguly, Mater. Res. Soc. Symp. Proc. 609, A19.6 (2000).

${ }^{11}$ R. W. Collins, J. Koh, H. Fujiwara, P. I. Rovira, A. S. Ferlauto, J. A. Zapien, C. R. Wronski, and R. Messier, Appl. Surf. Sci. 154, 217 (2000) 